\title{
Clinical utility of fulvestrant in the treatment of breast cancer: a report on the emerging clinical evidence
}

This article was published in the following Dove Press journal:

Cancer Management and Research

\section{Andrea Rocca' \\ Roberta Maltoni' \\ Sara Bravaccini ${ }^{2}$ \\ Caterina Donati ${ }^{3}$ \\ Daniele Andreis ${ }^{4}$}

'Breast Cancer Unit, Department of Medical Oncology, Istituto Scientifico Romagnolo per lo Studio e la Cura dei Tumori (IRST) IRCCS, ${ }^{2}$ CytoHisto-Molecular Pathology, Bioscience Laboratory, Istituto Scientifico Romagnolo per lo Studio e la Cura dei Tumori (IRST) IRCCS, ${ }^{3}$ Pharmacy, Istituto Scientifico Romagnolo per lo Studio e la Cura dei Tumori (IRST) IRCCS, ${ }^{4}$ Unit of Biostatistics and Clinical Trials, Istituto Scientifico Romagnolo per lo Studio e la Cura dei Tumori (IRST) IRCCS, Meldola, Italy
Correspondence: Andrea Rocca Breast Cancer Unit, Department of Medical Oncology, Istituto Scientifico Romagnolo per lo Studio e la Cura de Tumori (IRST) IRCCS, Via Maroncelli 40,

Meldola 470I4, Italy

Tel +39543739 100

Fax +39543739 I5।

Email andrea.rocca@irst.emr.it

\begin{abstract}
Fulvestrant is the first selective estrogen receptor (ER) downregulator available in clinical practice. It is a pure antiestrogen with no agonistic effects, leading to degradation of ER alpha, with activity in tamoxifen-resistant breast cancer (BC) models. Pharmacokinetic and pharmacodynamic studies and several postmarketing clinical trials led to the definition of the optimal dose at $500 \mathrm{mg}$ intramuscularly on days 1, 15, and 29 and then every 28 days. Targeting ER alpha, fulvestrant is a cornerstone of treatment in luminal BCs, whose growth is largely driven by the ER pathway. In endocrine therapy-naïve patients with hormone receptorpositive, HER2- advanced BC (ABC), fulvestrant yielded significantly longer progressionfree survival compared to anastrozole in the Phase III FALCON study. Due to its mechanism of action and pharmacokinetic properties, fulvestrant is an ideal backbone for combination therapies. Preclinical studies have shown synergism with drugs acting on signaling pathways involved in the development of endocrine resistance, among which the cyclin D/cyclindependent kinase 4-6/retinoblastoma pathway and the phosphatidylinositol 3-kinase (PI3K)/ Akt/mammalian target of rapamycin pathway, contributing to overcoming or delaying endocrine resistance. In the Phase III PALOMA-3 trial, a combination of the cyclin-dependent kinase 4/6 inhibitor palbociclib with fulvestrant significantly improved progression-free survival over fulvestrant alone in women with hormone receptor positive, HER2- ABC progressing during prior endocrine therapy. This led to approval of the combination in this clinical setting. Similar results were obtained with abemaciclib and ribociclib. Combination with pan-PI3K inhibitors, though showing some efficacy, was hampered by the toxicity of these agents, and studies in combinations with more selective inhibitors of the $\alpha$-catalytic subunit of PI3K are ongoing. Fulvestrant has shown partial activity also in patients with tumors harboring mutations of the ESRl gene. It is thus a key drug in the treatment of $\mathrm{ABC}$, whose role in combination with new targeted agents is still evolving.
\end{abstract}

Keywords: advanced breast cancer, endocrine therapy, metastatic, selective estrogen receptor downregulator, SERD, combination therapy

\section{Introduction}

Among neoplasms in women, breast cancer (BC) ranks first in incidence worldwide, first in mortality in less developed regions, and second in more developed ones. ${ }^{1}$ Although BC mortality is decreasing and the overall survival (OS) of metastatic disease is increasing, due to diagnostic and therapeutic improvements, the disease in its metastatic stage remains virtually incurable.

Different BC subtypes can be identified by "omics" techniques, ${ }^{2}$ first and foremost the "intrinsic" BC subtypes defined by gene-expression profiling., These include 
four main classes: the luminal A and luminal B tumors, whose growth is largely driven by the estrogen receptor (ER) pathway, and the human epidermal growth factor receptor 2 (HER2)-enriched and basal-like subtypes, which are not affected by the ER pathway. Luminal A tumors show high expression of genes related to the ER pathway (eg, ESR1, GATA3) and low expression of genes associated with cell proliferation, while luminal B tumors have lower expression of genes of the ER pathway and higher expression of genes associated with the cell cycle (eg, $C C N D 1$, encoding cyclin D1) and proliferation (eg, MKI67, encoding Ki67), as well as higher expression of growth-factor-receptor genes, including HER2 2, ${ }^{2,5}$ A surrogate definition of these subtypes is used in clinical practice, based on tumor expression of ER, progestin receptor (PR), the proliferative marker Ki67, and HER2, assessed by immunohistochemistry. ${ }^{7}$

\section{Current strategies for slowing cancer progression in women with luminal BC}

Given the role of the ER pathway in luminal BC, first-choice treatment is usually endocrine therapy, although endocrine resistance, either primary (relapse while in the first 2 years of adjuvant endocrine therapy or progression within first 6 months of first-line endocrine therapy for metastatic disease) or acquired (relapse while on adjuvant endocrine therapy after the first 2 years, relapse within 12 months of completing adjuvant endocrine therapy, or disease progression $\geq 6$ months after initiating endocrine therapy for metastatic disease), is a major obstacle to disease control. ${ }^{8}$ Several agents are available, the most important being: tamoxifen, a selective ER modulator with antagonistic but also partially agonistic action on ER; aromatase inhibitors (AIs), which inhibit the aromatase enzyme converting androgens into estrogens; and fulvestrant, a selective ER downregulator/degrader (SERD) with purer antagonistic and irreversible action on ER. Nonetheless, primary or acquired endocrine resistance ultimately affects all metastatic luminal BCs, often subtended by known biological alterations, such as cross talk between ER and growth-factor receptors, ${ }^{9}$ mutations/hyperactivity of the phosphatidylinositol 3-kinase $(\mathrm{PI} 3 \mathrm{~K}) /{ }^{10}$ protein kinase $\mathrm{B}(\mathrm{Akt}) /{ }^{11}$ mammalian target of rapamycin $(\mathrm{mTOR})^{12}$ pathway, hyperactivity of the cyclin $\mathrm{D} 1^{13}$ /cyclin-dependent kinase $(\mathrm{CDK}) 4$ and $6^{14} /$ retinoblastoma $(\mathrm{RB})^{15}$ pathway and ESR1 gene mutations. ${ }^{16}$ Several drug-combination strategies are being developed to overcome or delay the onset of endocrine resistance: combinations of endocrine agents with growth-factor-receptor inhibitors, CDK4/6 inhibitors,
PI3K inhibitors, or use of SERDs potentially active also in the presence of mutated ER.

Fulvestrant is the first SERD to enter the clinical arena and represents a key compound for endocrine treatment of BC and a suitable backbone for combination therapy with new targeted agents. In this paper, we review pharmacological properties and preclinical and clinical studies of fulvestrant alone and in combination with other agents, and provide a perspective on its current and future role in $\mathrm{BC}$ treatment.

\section{Pharmacology, mode of action, pharmacokinetics of fulvestrant Pharmacology}

Fulvestrant (ICI 182,780) is a steroidal molecule derived from $17 \beta$-estradiol by substitution of a hydrogen atom with an alkylsulfinylamide side chain in position $7 \alpha .{ }^{17}$ Fulvestrant acts as ER $\alpha$ antagonist, binding ER $\alpha$ competitively with estradiol, with a binding affinity that is $89 \%$ that of estradiol (much greater than the affinity of tamoxifen, which is $2.5 \%$ that of estradiol). ${ }^{17}$

The ER $\alpha$ molecule is composed of different domains: a ligand-binding domain (binding $17 \beta$-estradiol), a DNAbinding domain, a hinge or dimerization domain, and two transactivating domains (ligand-independent activation function [AF]-1 and the ligand-dependent AF2). ${ }^{18-20} \mathrm{ER} \alpha$ has different mechanisms of action: 1) working as a transcription factor (classical genomic action): activating specific "estrogen-response elements" in the promoters of target genes; 2) binding and activating other transcription factors (nonclassical genomic action); 3) being activated in a ligand-independent way by cross talk with receptor tyrosine-kinase pathways; or 4) exerting "nongenomic" actions whereby estrogens activate membrane-bound G protein coupled ERs (GPER, also known as GPR30) and their downstream signaling. Control of ER actions involves AF-domain recruitment of coregulators. While AF2 is activated by estrogen in ligand-dependent processes, ${ }^{21} \mathrm{AF} 1$ is activated by growth factors through activation of the mitogen activated protein kinase (MAPK). ${ }^{22}$

Binding of fulvestrant to ER $\alpha$ hampers ER dimerization, ${ }^{23}$ inhibits ER nuclear translocation ${ }^{24}$ and activation, and promotes ER degradation (ER downregulation), yielding complete inhibition of ER $\alpha$ signaling. Blocking both AF1 and AF2 (while selective ER modulators inhibit only AF2), fulvestrant is a pure $\mathrm{ER} \alpha$ antagonist, lacking any agonist activity, including any effect on the endometrium. ${ }^{25,26}$ Contrary to its action on $\mathrm{ER} \alpha$, fulvestrant causes a stabilization of $E R \beta$, a receptor isoform with growth-inhibitory properties, in BC cell lines. ${ }^{27,28}$ 
Preclinical studies have shown that fulvestrant downregulates the expression of ER $\alpha$ in ER-positive BC cell lines ${ }^{29}$ without reducing ER $\alpha$ gene (ESRl) transcripts and inhibits transcription of ER-responsive genes. ${ }^{30}$ Fulvestrant can also block the nongenomic actions of estradiol on GPER. ${ }^{31}$ These processes result in potent inhibition of the growth of ER-positive human BC cell lines, ${ }^{17}$ with activity also in tamoxifen-resistant lines ${ }^{32-34}$ and lack of cross-resistance with tamoxifen. ${ }^{35}$ The antitumor activity of fulvestrant was confirmed in xenograft models of ER-positive $\mathrm{BC}^{17,36}$ and found to be more effective than tamoxifen or estrogen withdrawal. ${ }^{37}$

\section{Pharmacodynamics}

Pharmacodynamic (PD) studies in women with early BC treated with a short preoperative course of short-acting fulvestrant and assessing biomarker changes between baseline biopsies and surgical samples have shown substantial reduction in the expression levels of ER, PR, and Ki67. ${ }^{29,38}$ In a randomized study comparing a single injection of long-acting fulvestrant at different doses $(50,125$, or $250 \mathrm{mg})$ with oral daily tamoxifen or placebo for 2-3 weeks before surgery, fulvestrant showed a dose-dependent reduction in ER, PR, and Ki67 expression in primary BC. ER downregulation at the $250 \mathrm{mg}$ dose was significantly higher compared to the tamoxifen arm, and tamoxifen produced an increase in PR expression, underlying the different mechanism of action. ${ }^{39}$

A further study involved 32 patients with advanced $\mathrm{BC}$ $(\mathrm{ABC})$ treated with first-line fulvestrant $250 \mathrm{mg}$ monthly who underwent repeated tumor biopsies. ${ }^{40}$ The clinical benefit (CB) rate (objective response [OR] or stable disease $[\mathrm{SD}] \geq 6$ months) was $81 \%$ and duration of response (DOR) was 25.8 months. Fulvestrant produced a decrease in Ki67 in 79\% of tumors, and lower Ki67 predicted longer DOR. ER and PR significantly decreased in all tumors, and there was loss of epidermal growth factor receptor (EGFR) and MAPK phosphorylation in $65 \%$ of tumors. At disease progression, ER remained low (although still present), while there was some recovery of Ki67 and EGFR/MAPK activity in 45\%-67\% of the patients.

The NEWEST (neoadjuvant endocrine therapy for women with estrogen-sensitive tumors) randomized, open-label, Phase II study compared high-dose (HD) fulvestrant (500 mg on days 0,14 , and 28 , then every 28 days) with fulvestrant 250 mg every 28 days administered for 16 weeks prior to surgery in 211 postmenopausal women with ER-positive local ABC. ${ }^{41}$ The primary objective was to compare reductions in $\mathrm{Ki} 67$ on tumor biopsy after 4 weeks of treatment. HD fulvestrant produced a greater reduction in Ki67 (78.8\% versus 47.4\%,
$P<0.0001)$ at 4 weeks, as well as a greater reduction in ER expression $(25.0 \%$ versus $13.5 \%, P=0.0002)$. OR rates, assessed at week 16 by $3 \mathrm{D}$ ultrasound, were $22.9 \%$ and $20.6 \%$ for fulvestrant 500 and $250 \mathrm{mg}$, respectively.

\section{Pharmacokinetics}

Fulvestrant is supplied as $250 \mathrm{mg} / 5 \mathrm{~mL}$ vials of long-acting compound for intramuscular (IM) injection, its low solubility limiting further drug concentration, and was initially approved at a dose of $250 \mathrm{mg}$ every 28 days. It is slowly absorbed after IM injection, with $99 \%$ bound to plasma lipoproteins and volume of distribution of $3-5 \mathrm{~L} / \mathrm{kg}$. ${ }^{42}$ Fulvestrant metabolism involves multiple transformations, similarly to endogenous steroids, and cytochrome p450 3A4 (CYP3A4 appears involved in its oxidation. Despite that, there are no known interactions with other drugs, including inducers and inhibitors of CYP3A4, and fulvestrant does not inhibit other CYP enzymes. Elimination is largely via the feces as metabolites and less than $1 \%$ through the urine. ${ }^{42}$ Fulvestrant has not been studied in patients with severe hepatic or renal impairment. Drug exposure may increase in the presence of mild-moderate liver impairment, and use with caution or dose reductions are recommended in these cases. No dose reductions are required in cases of mild or moderate renal impairment. ${ }^{42}$ Race, age, and body weight do not affect drug exposure significantly.

Early pharmacokinetic (PK) analyses at the initially approved dose (IAD) and schedule, with monthly depot IM injections of fulvestrant $250 \mathrm{mg}$, showed maintenance of therapeutic concentrations up to 28 days and an increase in mean area under the concentration-time curve (AUC) after repeated doses. ${ }^{43,44}$ Further PK evaluations were done in Phase III studies with fulvestrant IAD. After a single dose, the mean time to peak plasma concentration $\left(\mathrm{T}_{\max }\right)$ was 7 days, the mean AUC from day 0 to day $28\left(\mathrm{AUC}_{28}\right) 148 \mu \mathrm{g} *$ day/L, the mean maximum plasma concentrations $\left(\mathrm{C}_{\max }\right) 8.2 \mu \mathrm{g} / \mathrm{L}$, and the mean minimum plasma concentration $2.6 \mu \mathrm{g} / \mathrm{L} .{ }^{45}$ After repeated doses, the steady-state trough-concentration geometric mean increased from about 2.5 to about $6.5 \mu \mathrm{g} / \mathrm{L}$ over the first 6 months, reaching steady-state concentrations in the range of 6-9 $\mu \mathrm{g} / \mathrm{L}$. PK data are adequately described by a two-compartment kinetic model, with a biexponential decline, estimated disposition half-life of about 50 hours and steady-state $\mathrm{AUC}_{28}$ of about $300 \mu \mathrm{g}$ *day/L. ${ }^{45-47}$

The acknowledgment of a greater than twofold increase in steady-state concentrations and $\mathrm{AUC}_{28}$ over the first 6 months of therapy and the known dose-dependent downregulation of $\mathrm{ER} \alpha$ expression prompted the investigation of different 
dosing schedules to achieve therapeutic steady-state levels more rapidly and avoid potential early disease progressions due to inadequate drug levels. Based on PK models, a loading dose (LD) regimen involving the administration of $500 \mathrm{mg}$ IM at day 0 , followed by $250 \mathrm{mg}$ IM on days 14 and 28, then $250 \mathrm{mg}$ IM every 28 days, and an HD regimen of $500 \mathrm{mg}$ IM on days 0,14 , and 28 , then every 28 days were developed and tested in subsequent clinical trials. ${ }^{48}$ Comparison of PK parameters among the three regimens (IAD, LD, and HD) showed dose-proportional $\mathrm{C}_{\max }$ and AUC and faster achievement of steady-state concentrations with LD and HD within 1 month from treatment start. ${ }^{49-52}$

\section{Efficacy studies for fulvestrant as monotherapy or in combination therapy}

\section{Studies at the IAD}

Initial studies were conducted at the IAD of $250 \mathrm{mg}$ IM monthly (every $28 \pm 3$ days), in patients with hormone receptor (HR)-positive ABC pretreated with endocrine therapy, and have been reviewed in detail elsewhere. ${ }^{53,54}$ Phase II studies, like the Swiss Group for Clinical Cancer Research SAKK 21/00 trial and the North Central Cancer Treatment Group N0032 trial, reported CB rates of 30\%-35\%. ${ }^{55,56}$ Compassionate use programs showed $\mathrm{CB}$ in chemotherapy-pretreated patients, in more advanced lines of endocrine treatment, and in HER2-positive tumors. ${ }^{57,58}$ The main randomized clinical trials with fulvestrant are summarized in Table 1.

Two randomized Phase III trials, the open-label trial $0020^{59}$ carried out in Europe, Australia, and South Africa $(n=451$ patients) and the North American double-blind double-dummy trial $0021^{60}(n=400)$, compared fulvestrant IAD with anastrozole, in postmenopausal patients with endocrine-sensitive ABC (HR-positive, relapsed after $\geq 12$ months of adjuvant endocrine therapy, or with prior $\mathrm{CB}$ $\geq 3$ months in the first-line metastatic setting) progressing after prior endocrine therapy mainly with tamoxifen. In a prospectively planned combined analysis of the two trials on 851 patients, ${ }^{61}$ the median time to progression (TTP) was 5.5 months with fulvestrant and 4.1 months with anastrozole, with hazard ratio of 0.95 (95.14\% CI $0.82-1.10 ; P=0.48)$, fulfilling criteria for noninferiority of fulvestrant relative to anastrozole (upper one-sided confidence limit for TTP hazard ratio $\leq 1.25$ ), but not that of superiority. OR and $\mathrm{CB}$ rates did not differ between the two arms within subgroups of patients with or without visceral metastases. ${ }^{62}$ DOR was in favor of fulvestrant, ${ }^{61}$ but there were no differences in OS. ${ }^{63}$ These results led to registration of fulvestrant for treat- ment of patients with $\mathrm{ABC}$ relapsing or progressing on prior antiestrogen therapy.

In the first-line setting, fulvestrant IAD was compared with tamoxifen in a randomized Phase III trial in postmenopausal patients with HR-positive/unknown ABC previously untreated for advanced disease and who had completed adjuvant endocrine therapy from $\geq 12$ months. ${ }^{64}$ Contrary to what expected from preclinical studies, TTP was inferior, although not significantly, with fulvestrant compared to tamoxifen (median 6.8 and 8.3 months, hazard ratio 1.18, 95\% CI $0.98-1.44 ; P=0.088$ ). In a prospectively planned subset analysis of patients with HR-positive tumors ( $\approx 78 \%$ ), median TTP was 8.2 and 8.3 months (hazard ratio $1.10,95 \%$ CI $0.89-1.36 ; P=0.39$ ), showing similar efficacy of the two drugs, although inferiority of fulvestrant could not be ruled out (upper $95 \% \mathrm{CI}>1.25$ ). Only an exploratory unplanned subset analysis of patients with both ER-positive and PRpositive tumors showed results consistent with noninferiority of fulvestrant (hazard ratio $0.85,95 \% \mathrm{CI} 0.63-1.15 ; P=0.31$ ).

\section{Studies with LD and high dose}

Based on PD and PK studies showing dose-related drug exposure and biological effects, trials with higher doses of fulvestrant were conducted. The randomized Phase II Faslodex Investigation of Dose Evaluation in Estrogen Receptor-Positive Advanced Breast Cancer (FINDER) trials $1^{49}$ and $2,{ }^{50}$ carried out in Japanese and non-Japanese patients respectively, compared fulvestrant IAD with $\mathrm{LD}$ and $\mathrm{HD}$ in postmenopausal women with $\mathrm{HR}$-positive $\mathrm{ABC}$ recurring or progressing after prior endocrine therapy, reporting a trend toward improved efficacy with HD and LD compared to the IAD. They set the ground for the large confirmatory Phase III study Comparison of Fulvestrant In Recurrent or Metastatic Breast Cancer (CONFIRM), comparing fulvestrant HD versus the IAD in 736 postmenopausal women with ER-positive $\mathrm{ABC}$ who experienced disease progression during adjuvant or first-line endocrine therapy or within 1 year from completion of adjuvant endocrine therapy, about two-thirds of whom had acquired endocrine resistance and a third had primary resistance. ${ }^{65}$ PFS was significantly longer with the HD compared to the IAD (hazard ratio $0.80,95 \%$ CI $0.68-0.94 ; P=0.006$ ). Neither OR/CB rates nor adverse events (AEs) differed significantly between the two arms. At the final analysis, median OS was 26.4 months for the HD and 22.3 months for the IAD (hazard ratio $0.81,95 \%$ CI $0.69-0.96 ; P=0.02$ ) ${ }^{66}$ A post hoc analysis confirmed the improved PFS with fulvestrant HD versus IAD in both first-line and second-line treatment of ABC. ${ }^{67}$ Results of these studies led to worldwide approval of the $\mathrm{HD}$ as the standard fulvestrant dose. 
In the TransCONFIRM substudy, genome-wide transcriptomic analysis was conducted on primary tumor samples from 134 patients with Affymetrix microarrays (Santa Clara, CA, USA). ${ }^{68}$ High expression of most genes in the EGF-signaling pathway and FOXA1 transcription-factor network strongly predicted decreased PFS. An exploratory multivariate Cox analysis identified a set of 37 genes, among them the known regulator of ER activity TFAP2C, whose expression was independently associated with PFS.

The LD of fulvestrant was compared with exemestane in the Evaluation of Faslodex versus Exemestane Clinical Trial (EFECT) randomized, double-blind, Phase III trial in 693 postmenopausal women with HR-positive ABC progressing or recurring after nonsteroidal AI (NSAI). ${ }^{51} \mathrm{TTP}, \mathrm{OR}$, and $\mathrm{CB}$ were similar in the two arms, both in patients with AI-sensitive and AI-resistant tumors, although an unplanned retrospective analysis on AI-sensitive patients (OR or $\mathrm{SD} \geq 6$ months from first-line AI for ABC; approximately $60 \%$ of the entire patient population) suggested a possible benefit in TTP with fulvestrant.

Fulvestrant HD was compared with anastrozole as firstline treatment for HR-positive ABC in the randomized, open-label, Phase II study Fulvestrant First-Line Study Comparing Endocrine Treatments (FIRST), which enrolled 205 postmenopausal women. ${ }^{69}$ The primary end point, CB rate, did not differ between arms, but median TTP was 23.4 months with fulvestrant and 13.1 months with anastrozole (hazard ratio $0.66,95 \%$ CI $0.47-0.92 ; P=0.01$ ). ${ }^{70}$ Median OS was 54.1 months with fulvestrant and 48.4 months with anastrozole (hazard ratio $0.70,95 \%$ CI $0.50-0.98$; $P=0.04) .{ }^{71}$ These results were confirmed in the randomized, double-blind, Phase III Fulvestrant and Anastrozole Compared in Hormonal Therapy Naive Advanced Breast Cancer (FALCON) study comparing fulvestrant HD with anastrozole in 462 endocrine therapy-naïve, postmenopausal women with HR-positive ABC. ${ }^{72}$ Median PFS (the primary end point) was 16.6 months with fulvestrant and 13.8 months with anastrozole (hazard ratio $0.797,95 \%$ CI $0.637-0.999$; $P=0.0486$ ). OR and $\mathrm{CB}$ rates did not differ between the two arms, while DOR and duration of $\mathrm{CB}$ were longer with fulvestrant. The median OS was not reached in either arm, and the hazard ratio for death was 0.88 (95\% CI 0.63-1.22, $P=0.43)$. Benefit from fulvestrant was similar across most prespecified patient subgroups, but differed between patients with visceral versus those with nonvisceral disease: the PFS hazard ratio was 0.59 (95\% CI $0.42-0.84)$ in patients with nonvisceral disease (median PFS 22.3 months with fulvestrant versus 13.8 months with anastrozole), and 0.99
(95\% CI 0.74-1.33) in patients with visceral disease (median PFS 13.8 months with fulvestrant versus 15.9 months with anastrozole, post hoc interaction test $P=0.009$ ). Most AE rates were similar between the two arms, but arthralgia was more common with fulvestrant (17\%) than with anastrozole $(10 \%)$. The FALCON study established fulvestrant HD as the most efficacious endocrine agent in postmenopausal women with HR-positive ABC not previously treated with endocrine therapy.

Fulvestrant has been tested at even higher doses, of 750 mg IM, in premenopausal patients, to counteract higher premenopausal estradiol levels, with evidence of activity. ${ }^{73}$ Nonetheless, due to the difficulty of administration of the large volume of drug solution, this dosage was not further developed, and use in premenopausal women requires combination with a gonadotropin-releasing hormone $(\mathrm{GnRH})$ analog. The use of fulvestrant in male $\mathrm{BC}$ has been reported mainly in small case series, with evidence of activity. ${ }^{74}$ In a pooled analysis on 31 cases reported in the literature, the OR rate was $26 \%$ and the rate of SD $48 \%$. $^{75}$

\section{Studies of combination therapy with other endocrine agents}

Because fulvestrant is a competitive inhibitor of $\mathrm{ER} \alpha$, lowering estradiol levels can increase its activity, as shown by preclinical studies. ${ }^{76}$ However, studies combining fulvestrant and AIs have produced contradictory results. A randomized presurgical PD study compared fulvestrant HD plus anastrozole versus either agent alone administered for 2-3 weeks before surgery in 121 patients with operable, HR-positive BC. ${ }^{77}$ All treatments significantly reduced ER, $\mathrm{PR}$, and Ki67 expression, and the combination reduced ER more than anastrozole alone, but not more than fulvestrant alone. The randomized Phase III Fulvestrant and Anastrozole Combination Therapy (FACT) trial compared fulvestrant LD plus anastrozole with anastrozole alone in 514 women with HR-positive BC at first relapse. About two-thirds had received adjuvant tamoxifen (only eight received adjuvant NSAIs), and disease relapse occurred within 12 months from the end of adjuvant therapy in half of them; a third received no adjuvant endocrine therapy. There were no differences in efficacy between the two arms. ${ }^{78}$ The similar randomized Phase III SWOG 0226 trial enrolled 694 postmenopausal women with previously untreated HR-positive $\mathrm{ABC}$, stratified according to prior adjuvant endocrine therapy (40\% had received adjuvant tamoxifen and 60\% no adjuvant endocrine therapy). ${ }^{79}$ This trial showed better PFS and OS with the combination, without any increase in 
Table I Main randomized clinical trials in postmenopausal women with hormone receptor-positive, HER2-negative advanced breast cancer

\begin{tabular}{|c|c|c|c|c|c|c|}
\hline \multirow{2}{*}{$\begin{array}{l}\text { Study } \\
\text { acronyms }\end{array}$} & \multirow[t]{2}{*}{ Study } & \multicolumn{5}{|c|}{ Single-agent fulvestrant } \\
\hline & & Design & $\mathbf{n}$ & $\begin{array}{l}\text { Menopausal } \\
\text { status* }\end{array}$ & Treatment & ET line *** $^{*}$ \\
\hline 0020 & Howell et al ${ }^{59}$ & OL Phase III & 451 & Post & Fulvestrant IAD vs anastrozole & Ist-2nd \\
\hline 0021 & Osborne et al ${ }^{60}$ & DB Phase III & 400 & Post & Fulvestrant IAD vs anastrozole & Ist-2nd \\
\hline \multirow[t]{2}{*}{0025} & Howell et $\mathrm{a}^{64}$ & DB Phase III & 587 (HR+/unknown) & Post & Fulvestrant IAD vs tamoxifen & Ist \\
\hline & & & $459 \mathrm{HR}^{+}$ & & & \\
\hline CONFIRM & Di Leo et $a^{65,66}$ & DB Phase III & 736 & Post & Fulvestrant $\mathrm{HD}$ vs fulvestrant IAD & Ist-2nd \\
\hline EFECT & Chia et $\mathrm{a}^{51}$ & DB Phase III & 693 & Post & Fulvestrant LD vs exemestane & Ist-2nd \\
\hline FIRST & Robertson et a ${ }^{|69-7|}$ & OL Phase II & 205 & Post & Fulvestrant HD vs anastrozole & Ist \\
\hline \multirow[t]{2}{*}{ FALCON } & Robertson et $\mathrm{al}^{72}$ & DB Phase III & 462 & Post & Fulvestrant HD vs anastrozole & Ist \\
\hline & & \multicolumn{5}{|c|}{ Fulvestrant + other endocrine agents } \\
\hline FACT & Bergh et $\mathrm{a}^{78}$ & OL Phase III & 514 & Pre/post & $\begin{array}{l}\text { Fulvestrant LD + anastrozole vs } \\
\text { anastrozole }\end{array}$ & Ist \\
\hline SWOG 0226 & Mehta et al $\left.\right|^{79}$ & OL Phase III & 694 & Post & $\begin{array}{l}\text { Fulvestrant LD + anastrozole vs } \\
\text { anastrozole }\end{array}$ & Ist \\
\hline \multirow[t]{3}{*}{ SoFEA } & Johnston et al ${ }^{80}$ & DB Phase III & 723 & Post & $\begin{array}{l}\text { Fulvestrant LD + anastrozole vs } \\
\text { fulvestrant } L D+\text { placebo }\end{array}$ & Ist-2nd \\
\hline & & & & & $\begin{array}{l}\text { Fulvestrant LD + placebo vs } \\
\text { exemestane }\end{array}$ & \\
\hline & & \multicolumn{5}{|c|}{ Fulvestrant + inhibitors of growth-factor-receptor pathways } \\
\hline \multirow[t]{2}{*}{$\begin{array}{l}\text { CALGB 40302/ } \\
\text { ALLIANCE }\end{array}$} & Burstein et $\mathrm{a}^{87}$ & DB Phase III & 295 & Post & $\begin{array}{l}\text { Fulvestrant } \mathrm{HD}+\text { lapatinib vs } \\
\text { fulvestrant } \mathrm{HD}+\text { placebo }\end{array}$ & Ist-2nd \\
\hline & & \multicolumn{5}{|c|}{ Fulvestrant + inhibitors of MAPK-ERKI/2 and PI3K-mTOR pathways } \\
\hline SAKK $21 / 08$ & Zaman et a $\left.\right|^{90}$ & DB Phase II & 46 & Post & $\begin{array}{l}\text { Fulvestrant } \mathrm{HD}+\text { selumetinib vs } \\
\text { fulvestrant } \mathrm{HD}+\text { placebo }\end{array}$ & Ist-2nd \\
\hline BELLE 2 & Baselga et $\mathrm{al}^{95}$ & DB Phase III & $\mathrm{I}, 147$ & Post & $\begin{array}{l}\text { Fulvestrant } H D+\text { buparlisib vs } \\
\text { fulvestrant } H D+\text { placebo }\end{array}$ & Ist-2nd \\
\hline BELLE 3 & Di Leo et a $\left.\right|^{96}$ & DB Phase III & $432(2: 1)$ & Post & $\begin{array}{l}\text { Fulvestrant HD + buparlisib vs } \\
\text { fulvestrant } H D+\text { placebo }\end{array}$ & 2nd-4th \\
\hline FERGI & Krop et $\mathrm{a}^{98}$ & DB Phase II & 168 & Post & $\begin{array}{l}\text { Fulvestrant } \mathrm{HD}+\text { pictilisib vs } \\
\text { fulvestrant } \mathrm{HD}+\text { placebo }\end{array}$ & Ist-4th \\
\hline \multirow[t]{2}{*}{ PrECOG 0102} & Kornblum et al ${ }^{102}$ & DB Phase II & $|3|$ & Post & $\begin{array}{l}\text { Fulvestrant } \mathrm{HD}+\text { everolimus vs } \\
\text { fulvestrant } \mathrm{HD}+\text { placebo }\end{array}$ & Ist-3rd \\
\hline & & \multicolumn{5}{|c|}{ Fulvestrant + CDK4/6 inhibitors } \\
\hline PALOMA 3 & Turner et al ${ }^{104-109}$ & DB Phase III & $521(2: 1)$ & Pre/post & $\begin{array}{l}\text { Fulvestrant } H D+\text { palbociclib vs } \\
\text { fulvestrant } H D+\text { placebo }\end{array}$ & Ist-3rd \\
\hline \multirow[t]{2}{*}{ MONARCH 2} & Sledge et al ${ }^{\prime \prime \prime}$ & DB Phase III & $669(2: 1)$ & Pre/post & $\begin{array}{l}\text { Fulvestrant } \mathrm{HD}+\text { abemaciclib vs } \\
\text { fulvestrant } \mathrm{HD}+\text { placebo }\end{array}$ & Ist-2nd \\
\hline & & \multicolumn{5}{|c|}{ Fulvestrant + angiogenesis inhibitors and multitargeting tyrosine-kinase inhibitors } \\
\hline LEA & Martín et al ${ }^{117}$ & OL Phase III & 380 & Post & $\begin{array}{l}\text { Fulvestrant HD or letrozole vs } \\
\text { fulvestrant HD or letrozole }+ \\
\text { bevacizumab }\end{array}$ & Ist \\
\hline CTK $1258 \mathrm{~A} 2210$ & Musolino et al ${ }^{119}$ & DB Phase II & 97 & Post & $\begin{array}{l}\text { Fulvestrant } \mathrm{HD}+\text { dovitinib vs } \\
\text { fulvestrant } \mathrm{HD}+\text { placebo }\end{array}$ & Ist-2nd \\
\hline
\end{tabular}

Notes: *Premenopausal patients also received a GnRH analog; **for advanced disease; ***disease progression while on or $\leq 12$ months after the end of adjuvant endocrine therapy or $\leq I$ month after the end of endocrine therapy for advanced disease.

Abbreviations: ET, endocrine therapy; CBR, clinical benefit rate; PFS, progression-free survival; TTP, time to progression; OS, overall survival; DCR, disease-control rate; $\mathrm{DB}$, double-blind; OL, open-label; IAD, initially approved dose; LD, loading dose; HD, high dose; MAPK, mitogen activated protein kinase; HER2, human epidermal growth factor receptor 2; GnRH, gonadotropin-releasing hormone; PI3K, phosphatidylinositol 3-kinase; mTOR, mammalian target of rapamycin; NA, not assessed; ERK, extracellular signal-regulated kinase; NS, not significant. 


\begin{tabular}{|c|c|c|c|c|c|c|}
\hline $\begin{array}{l}\text { PD to prior } \\
\text { ET*** }\end{array}$ & $\begin{array}{l}\text { Primary } \\
\text { end point }\end{array}$ & CBR (\%) & $\begin{array}{l}\text { Median TTP/PFS } \\
\text { (months) }\end{array}$ & HR (95\% Cl) & Median OS & HR (95\% Cl) \\
\hline Yes & TTP & 43.5 vs $40.9(P=0.5 \mathrm{I})$ & 5.5 vs 4.1 & $0.95(0.82-1.10)$ & NA & NA \\
\hline Yes & TTP & & & $P=0.48$ & & \\
\hline \multirow[t]{2}{*}{ No } & TTP & 54 vs 62 & 6.8 vs 8.3 & $\begin{array}{l}\text { I. } 18(0.98-1.44), \\
P=0.088\end{array}$ & 36.9 vs 38.7 & $1.29(1.01-1.64), P=0.04$ \\
\hline & & 57 vs 63 & 8.2 vs 8.3 & $\begin{array}{l}1.10(0.89-1.36), \\
P=0.39\end{array}$ & 39.3 vs 40.7 & $1.16(0.88-1.54), P=0.30$ \\
\hline Yes & PFS & 45.6 vs 39.6 & 5.5 vs 6.5 & $\begin{array}{l}0.80(0.68-0.94), \\
P=0.006\end{array}$ & 26.4 vs 22.3 & $0.8 \mathrm{I}(0.69-0.96), P=0.02$ \\
\hline Yes & TTP & 32.2 vs 31.5 & 3.7 vs 3.7 & $\begin{array}{l}0.93(0.819-1.133) \\
P=0.65\end{array}$ & NA & NA \\
\hline No & CBR & 72.5 vs $67.0(P=0.386)$ & 23.4 vs 13.1 & $\begin{array}{l}0.66(0.47-0.92), \\
P=0.01\end{array}$ & 54.1 vs 48.4 & $0.70(0.50-0.98), P=0.04$ \\
\hline No & PFS & 78 vs $74(P=0.3045)$ & 16.6 vs 13.8 & $\begin{array}{l}0.797(0.637-0.999) \\
P=0.0486\end{array}$ & NA & NA \\
\hline Yes/no & TTP & 55.0 vs $55.1(P=0.99)$ & 10.8 vs 10.2 & $\begin{array}{l}0.99(0.8 I-1.20), \\
P=0.91\end{array}$ & 37.8 vs 38.2 & $1.0(0.76-1.32), P=1.00$ \\
\hline No & PFS & 73 vs 70 & 15.0 vs 13.5 & $\begin{array}{l}0.80(0.68-0.94), \\
P=0.007\end{array}$ & 47.7 vs 41.3 & $0.81(0.65-1.00), P=0.05$ \\
\hline \multirow[t]{2}{*}{ Yes } & PFS & 34 vs $32(P=0.75)$ & 4.4 vs 4.8 & $\begin{array}{l}1.00(0.83-1.21), \\
P=0.98\end{array}$ & 20.2 vs 19.4 & $0.95(0.76-1.17), P=0.61$ \\
\hline & & 32 vs $27(P=0.27)$ & 4.8 vs 3.4 & $\begin{array}{l}0.95(0.79-I .14), \\
P=0.56\end{array}$ & 19.4 vs 21.6 & I .05 (0.84-I.29), $P=0.68$ \\
\hline Yes & PFS & NA & 4.7 vs 3.8 & $\begin{array}{l}1.04(0.82-1.33), \\
P=0.37\end{array}$ & 30.0 vs 26.4 & $0.91(0.68-1.21), P=0.25$ \\
\hline Yes & DCR & NA & 3.7 vs 5.6 & NA & 22.9 vs 19.4 & NA \\
\hline Yes & PFS & 43.8 vs 42.0 & 6.9 vs 5.0 & $\begin{array}{l}0.78(0.67-0.89), \\
P=0.00021\end{array}$ & NA & NA \\
\hline Yes & PFS & 25 vs 15 & 3.9 vs 1.8 & $\begin{array}{l}0.67(0.53-0.84), \\
P=0.0003\end{array}$ & NA & NA \\
\hline Yes & PFS & 24.7 vs $17.7(P=0.27)$ & 6.6 vs 5.1 & $\begin{array}{l}0.74(0.52-1.06), \\
P=0.096\end{array}$ & NA & NA \\
\hline Yes & PFS & NA & 10.4 vs 5.1 & $\begin{array}{l}0.60(0.40-0.92), \\
P=0.02\end{array}$ & NA & NA \\
\hline Yes & PFS & 67 vs $40(P<0.000 I)$ & 9.5 vs 4.6 & $\begin{array}{l}0.46(0.36-0.59), \\
P<0.0001\end{array}$ & NA & NA \\
\hline Yes & PFS & 72.2 vs $56.1(P<0.001)$ & I6.4 vs 9.3 & $\begin{array}{l}0.553(0.449-0.68 \mathrm{I}) \\
P<0.00 \mathrm{I}\end{array}$ & NA & NA \\
\hline Yes/no & PFS & 67 vs $77(P=0.04 I)$ & 14.4 vs 19.3 & $\begin{array}{l}0.83(0.65-1.06) \\
P=0.126\end{array}$ & 51.8 vs 52.1 & $0.87(0.58-1.32), P=0.518$ \\
\hline Yes & PFS & NA & 5.5 vs 5.5 & $\begin{array}{l}0.68(0.4 \mid-I .14), \\
\text { NS }\end{array}$ & NA & NA \\
\hline
\end{tabular}


toxicity. In an unplanned subgroup analysis, the combination was significantly better only in patients who had not received prior tamoxifen, although the interaction between the treatment arm and adjuvant endocrine therapy was not significant. The three-arm randomized trial Study of Faslodex with or without concomitant Arimidex vs Exemestane (SOFEA) trial compared fulvestrant LD plus anastrozole with fulvestrant LD plus placebo and with exemestane alone in 723 patients with HR-positive ABC who progressed after at least 12 months of adjuvant NSAI or at least 6 months of NSAI first-line treatment for ABC. ${ }^{80}$ There were no differences in PFS among the three arms, but in a retrospective analysis patients with ESR 1 mutations showed better PFS with fulvestrant than with exemestane. ${ }^{81}$ Based on these data, the combination of fulvestrant plus anastrozole may be offered to endocrine therapy-naïve patients. ${ }^{8}$ Nevertheless its prescription is off-label in some countries, and the preferred fulvestrant combination is likely with other targeted agents.

\section{Studies of combination therapy with drugs targeting growth-factor-receptor pathways}

The cross talk between the ER pathway and several growthfactor-signaling pathways is a common mediator of endocrine resistance. ${ }^{9}$ Fulvestrant, degrading ER, may block this cross talk and potentially work better than tamoxifen in HER2-overexpressing BC, and has shown some activity as monotherapy in HER2-positive, HR-positive BC. ${ }^{82}$ Preclinical studies found that the combination of fulvestrant with EGFR, HER2, or pan-HER inhibitors may be synergistic and overcome or delay the development of fulvestrant resistance, ${ }^{83,84}$ although clinical experiences with these combinations have been mostly disappointing. The EGFR inhibitor gefitinib has been combined with fulvestrant plus anastrozole in a small randomized Phase II neoadjuvant study, leading to a significant reduction in Ki67 after 3 weeks of therapy, ${ }^{85}$ but the clinical utility of this combination seems limited. ${ }^{86}$ The dual HER1-HER2 tyrosine-kinase inhibitor lapatinib did not improve results when added to fulvestrant in the randomized Phase III study CALGB 40302/Alliance in 295 patients with HR-positive ABC with any HER2 status pretreated with one or two lines of endocrine therapy for $\mathrm{ABC}$ and sensitive to previous AIs. Similar results were obtained in the small subgroup (18\%) with HER2-positive disease. ${ }^{87}$ The monoclonal antibody ganitumab, targeting the insulin-like growth factor receptor 1 (IGF-1R), did not improve PFS and worsened OS, when added to fulvestrant or exemestane in a randomized Phase II study. ${ }^{88}$

\section{Studies of combination therapy with drugs targeting the MAPK-ERKI/2 and PI3K-Akt-mTOR pathways}

Activation of signaling pathways downstream of growthfactor receptors, including $\mathrm{MAPK}-\mathrm{ERK} 1 / 2^{89}$ and $\mathrm{PI} 3 \mathrm{~K}-$ Akt-mTOR, ${ }^{10-12}$ is also implicated in endocrine resistance. MAPK-ERK1/2 phosphorylates AF1, leading to ligand-independent ER activation, and ERK1/2 activation is involved in fulvestrant resistance. ${ }^{89}$ The activity and safety of the MAP2K MEK1/2 inhibitor selumetinib in combination with fulvestrant were assessed in a randomized, double-blind, Phase II clinical trial in postmenopausal women with HR-positive, HER2negative $\mathrm{ABC}$ progressing after one line of endocrine therapy with an aromatase inhibitor. ${ }^{90}$ The main end point, CB rate, was worse with selumetinib than with placebo. ${ }^{91}$ A possible biological explanation of these results is that MEK inhibition reduces the activation of PTEN, leading to accumulation of phosphatidylinositol-3-phosphate and activation of Akt. ${ }^{91}$

Mutations of PIK3CA, the gene encoding the $\mathrm{p} 110 \alpha$ catalytic subunit of $\mathrm{PI} 3 \mathrm{~K}$, are the most frequent mutations in luminal $\mathrm{BC}$ and often lead to constitutive activity of the enzyme. ${ }^{2}$ In preclinical studies, the combination of fulvestrant $\mathrm{HD}$ and PI3K inhibitors showed synergistic activity and delayed endocrine resistance. ${ }^{92,93}$

A combination of the pan-PI3K inhibitor buparlisib (BKM120) targeting all 4 isoforms of PI3K ( $\alpha, \beta, \gamma$, and $\delta$ ) with fulvestrant $\mathrm{HD}^{94}$ was compared with fulvestrant $\mathrm{HD}$ plus placebo in the randomized, double-blind, Phase III study BELLE-2 in 1,147 postmenopausal women with HR-positive, HER2-negative ABC progressing on or shortly after $(\leq 12$ months in the adjuvant and $\leq 1$ month in the metastatic setting) prior AI. ${ }^{95}$ Median PFS was 6.9 months with buparlisib and 5.0 months with placebo (hazard ratio $0.78,95 \% \mathrm{CI}$ $0.67-0.89 ; P=0.0002$ ). In a planned exploratory subgroup analysis, PFS was significantly longer in the buparlisib arm in patients with $P I K 3 C A$ mutations detected in circulating tumor DNA (ctDNA), but not in those with wild-type PIK3CA. The companion randomized (2:1), double-blind, Phase III trial BELLE-3 compared fulvestrant HD plus buparlisib with fulvestrant HD plus placebo in 432 postmenopausal women with HR-positive, HER2-negative $\mathrm{ABC}$ pretreated with an $\mathrm{AI}$ and relapsing $\leq 30$ days after the end of treatment with an endocrine agent in combination with an mTOR inhibitor (mostly everolimus). ${ }^{96}$ As activation of mTOR elicits a negative feedback inhibiting PI3K and Akt, mTOR inhibition, releasing this negative feedback, leads to activation of PI3K and Akt, and ultimately to resistance to mTOR inhibitors. ${ }^{97}$ The BELLE-3 
trial aimed to assess the potential of PI3K inhibition to revert resistance to mTOR inhibitors and endocrine therapy. The combination of fulvestrant and buparlisib significantly improved PFS (median 3.9 versus 1.8 months, hazard ratio 0.67 , 95\% CI 0.53-0.84; one-sided $P=0.0003$ ). Benefit from buparlisib was greater in patients with $P I K 3 C A$-mutant tumors than in those with wild-type PIK3CA, either when PIK3CA status was assessed on ctDNA or on primary tumor tissue, although the treatment by PIK3CA status-interaction test was significant only for PIK3CA status assessed on tumor tissue. Buparlisib benefit was also marginally greater in patients with visceral disease than in those without and in patients who had no $\mathrm{CB}$ from previous mTOR inhibitor than in those who had $\mathrm{CB}$. Despite the hints of efficacy, because of the toxicity of buparlisib (transaminitis, hyperglycemia, rash, mood disorders) the development of this regimen has been abandoned in favor of combinations with more selective, $\alpha$-specific PI3K inhibitors.

Pictilisib, another pan-PI3K inhibitor, was evaluated in the randomized, double-blind, Phase II clinical trial FERGI comparing fulvestrant HD plus pictilisib with fulvestrant HD plus placebo in postmenopausal women with HR-positive, HER2-negative $\mathrm{ABC}$ resistant to $\mathrm{AI} .{ }^{98}$ Two cohorts of patients were recruited: 168 patients with any PIK3CA status and 61 with $P I K 3 C A$-mutant tumors. No significant differences in PFS or other end points were found between the two arms in both cohorts. Frequent dose modifications for toxicity could have reduced the efficacy of pictilisib. Studies are ongoing combining fulvestrant with $\alpha$-specific PI3K inhibitors, which have been shown to be active on PIK3CA-mutant tumors, such as alpelisib ${ }^{99}$ and taselisib. ${ }^{100}$ In the double blind phase III Sandpiper study 516 postmenopausal patients with HR-positive, HER2-negative, PIK3CA mutated ABC, who had disease recurrence or progression during or after an aromatase inhibitor, were randomized 2:1 to fulvestrant plus taselisib (a beta-sparing PI3K inhibitor active on mutant PIK3CA) or fulvestrant plus placebo. Median PFS was 7.4 versus 5.4 months (hazard ratio 0.7, 95\% CI 0.56-0.89, $P=0.0037$ ), respectively. This came at the cost of increased grade $\geq 3$ and serious adverse events, mainly gastro-intestinal and hyperglycemia, attributed to partial delta and gamma PI3K isoforms inhibition. ${ }^{101}$

The pan-Akt allosteric inhibitor MK2206 has been tested in combination with anastrozole and/or fulvestrant in a Phase IB study, yielding a CB in eleven of 30 (36.7\%) patients with HR-positive, HER2-negative ABC. ${ }^{102}$ The mTOR inhibitor everolimus in combination with fulvestrant HD was compared with placebo plus fulvestrant HD in the randomized, double-blind, Phase II trial PrECOG 0102 in 130 postmenopausal women with HR-positive, HER2-negative
ABC progressing on AI. PFS was significantly improved from a median of 5.1 months with placebo to 10.4 months with everolimus (hazard ratio $0.61,95 \%$ CI $0.40-0.92 ; P=0.02$ ). ${ }^{103}$

\section{Studies of combination therapy with drugs targeting the cyclin D-CDK4/6-Rb pathway}

Alterations of genes involved in the cyclin D-CDK4/6-Rb pathway are frequent in $\mathrm{BC}$ and contribute to endocrine resistance. ${ }^{2,15,93} \mathrm{CDK} 4 / 6$ inhibitors are active particularly in luminal BC cell lines, synergize with endocrine agents, and contribute to overcome or delay endocrine resistance. ${ }^{14,104}$ Three CDK4/6 inhibitors have undergone clinical development: palbociclib, ribociclib, and abemaciclib. In the randomized, double-blind, Phase III PALOMA-3 trial, 521 women with HR-positive, HER2-negative ABC progressing during or shortly after ( $\leq 12$ months in the adjuvant and $\leq 1$ month in the metastatic setting) prior endocrine therapy were randomized 2:1 to palbociclib plus fulvestrant $\mathrm{HD}$ versus placebo plus fulvestrant $\mathrm{HD}$, with premenopausal women receiving also a GnRH agonist. ${ }^{105,106}$ Seventy-nine percent of patients had acquired endocrine resistance and $21 \%$ had primary resistance. Median PFS was 9.5 months with palbociclib versus 4.6 months with placebo (hazard ratio $0.46,95 \%$ CI $0.36-$ $0.59 ; P<0.0001)$. The $\mathrm{OR}$ rate, time to response, and $\mathrm{CB}$ rate were also significantly improved. Benefit was independent of the degree of endocrine sensitivity, menopausal status, ${ }^{107}$ visceral metastases, ${ }^{108}$ PIK3CA, and ESR1 status (mutated vs wild-type) ${ }^{81}$ AEs were more frequent with the combined treatment, particularly leuconeutropenia, but toxicity was manageable ${ }^{109}$ and quality of life (QoL) better in the palbociclib arm. ${ }^{110}$ Results from the PALOMA-3 trial have led to the approval of the combination of fulvestrant plus palbociclib (plus a GnRH agonist in premenopause) in women with HR-positive, HER2-negative ABC who have received prior endocrine therapy.

A combination of fulvestrant and palbociclib with trastuzumab and pertuzumab (plus GnRH agonist in premenopause) has been explored as neoadjuvant treatment in a Phase II trial in patients with HER2-positive, ER-positive early, or local ABC, with reduction in $\mathrm{Ki67}$ as the main end point. ${ }^{111}$ In 30 evaluable patients, geometric mean Ki67 expression significantly decreased from 31.9 at baseline to 4.3 at week 2 (assessed on tumor biopsies) and was 12.1 at surgery. Clinical OR was achieved in $97 \%$ of patients, and the rate of pathological complete response in the breast and axilla was $27 \%$, highlighting the potential of chemotherapyfree regimens to induce tumor eradication in some cases. 


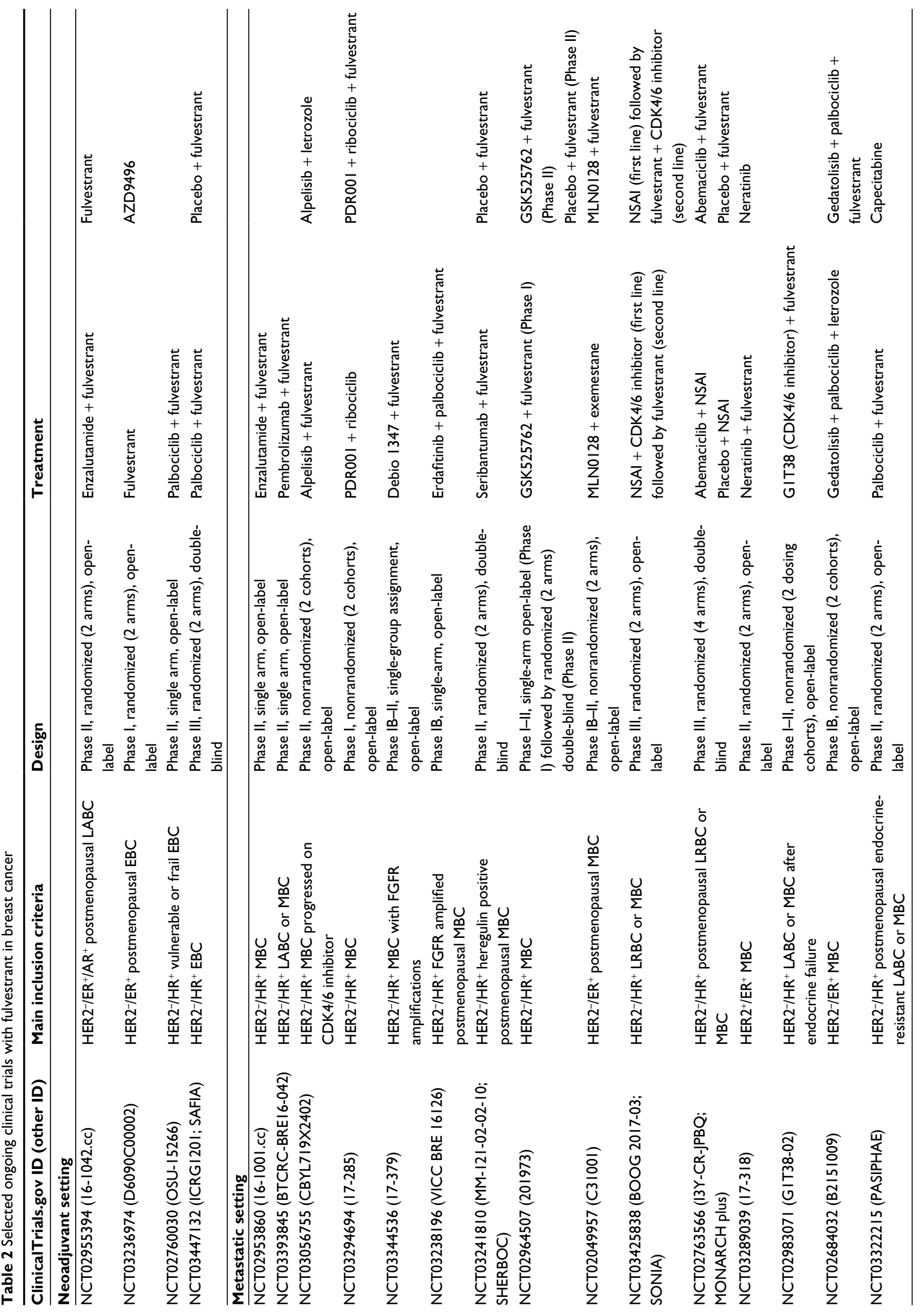




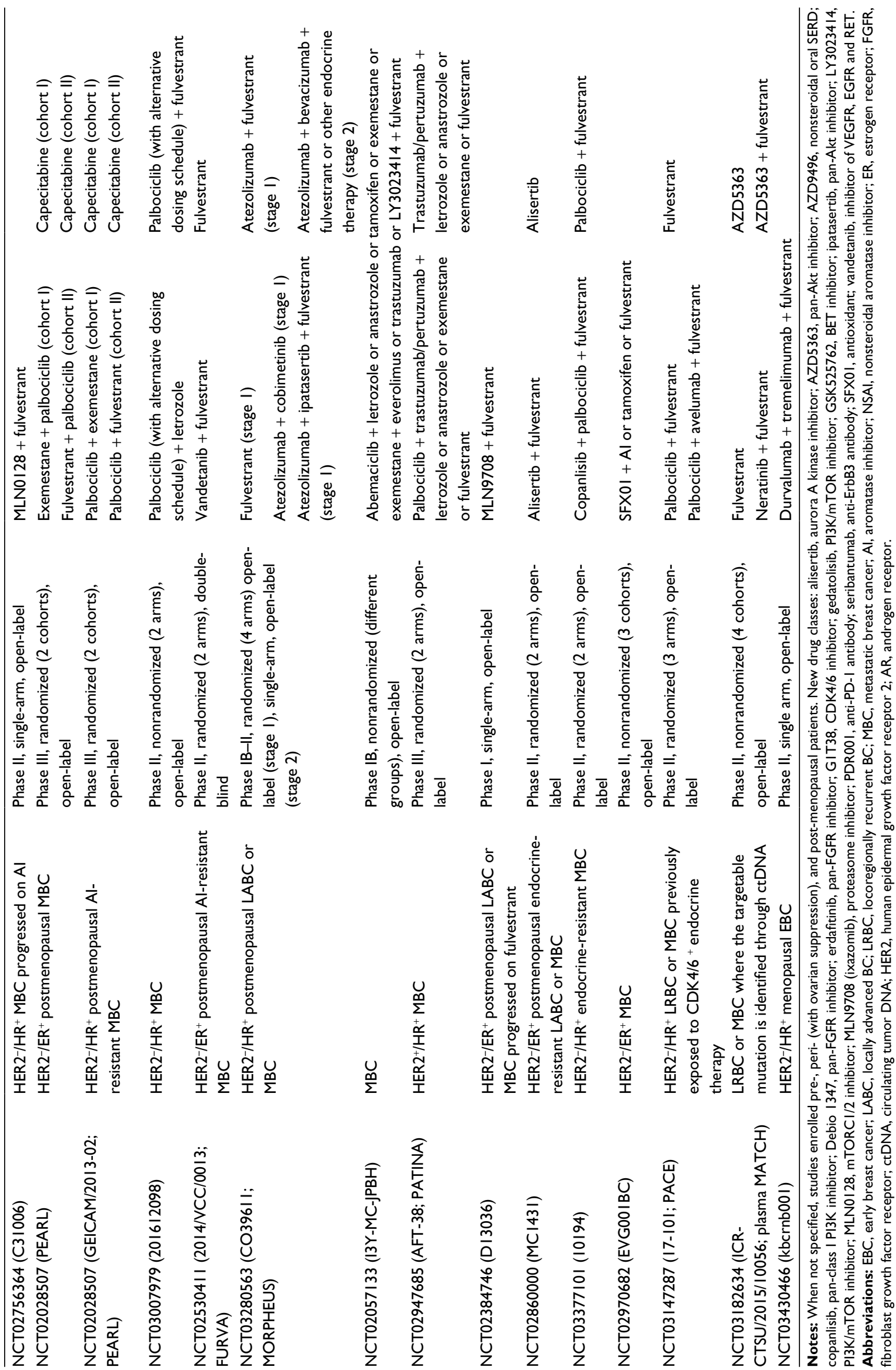


The randomized (2:1), double-blind, Phase III clinical trial MONARCH 2 compared fulvestrant HD plus abemaciclib with fulvestrant HD plus placebo in 669 women with HR-positive, HER2-negative ABC progressing during or $\leq 12$ months after the end of adjuvant endocrine therapy or during first-line endocrine therapy for ABC, 25\% of whom had primary endocrine resistance. ${ }^{12}$ Median PFS was 16.4 months with abemaciclib versus 9.3 months with placebo (hazard ratio $0.553,95 \%$ CI $0.449-0.681 ; P<0.001$ ). The OR rate in patients with measurable disease was $48.1 \%$ with abemaciclib and $21.3 \%$ in the placebo arm $(P<0.001)$. Benefit from abemaciclib was independent of type of endocrine resistance. Abemaciclib added some toxicity, particularly in terms of diarrhea and neutropenia, albeit manageable. Based on these results, abemaciclib has been approved by the US Food and Drug Administration (and is under evaluation by the European Medicines Agency) in combination with fulvestrant for treatment of women with HR-positive, HER2-negative ABC with disease progression following endocrine therapy. In the recently published double blind phase III Monaleesa-3 study 726 post-menopausal patients with HR-positive, HER2-negative ABC, who were treatmentnaïve for $A B C$ or had received up to one line of endocrine therapy for $\mathrm{ABC}$, were randomized 2:1 to fulvestrant plus ribociclib or fulvestrant plus placebo. Median PFS was 20.5 months versus 12.8 months (hazard ratio $0.593,95 \%$ CI $0.480-0.732, P<0.001)$, respectively, and ORR was also improved. Results were similar in patients treatment-naïve and in those pretreated with endocrine therapy for ABC. The combination of ribociclib plus fulvestrant represents therefore another option for first- or second-line treatment in HR-positive, HER2-negative ABC. ${ }^{113}$

Preclinical studies show the potential efficacy of a triple combination with an endocrine agent plus a CDK4/6 inhibitor and a PI3K inhibitor, both in vitro and in patient-derived tumor xenografts. ${ }^{114,115}$ Phase IB/II studies are exploring such triple-drug combination with fulvestrant, ribociclib, and PI3K inhibitors (eg, alpelisib and buparlisib) ${ }^{116}$ or PI3K/mTOR inhibitors (eg, gedatolisib) ${ }^{117}$ (Table 2).

\section{Studies of combination therapy with angiogenesis inhibitors and multitargeting tyrosine-kinase inhibitors}

The combination of an endocrine agent, either fulvestrant or letrozole, with the anti-vascular endothelial growth factor (VEGF) monoclonal antibody bevacizumab was compared with endocrine therapy alone in the randomized, open-label, Phase III trial letrozole/fulvestrant and avastin
(LEA) in 374 postmenopausal women with HR-positive, HER2-negative ABC in a first-line metastatic setting. The combination failed to improve PFS significantly, which was the primary end point, although there was an improvement in OR and CB rates. ${ }^{118}$ Similarly, the multitargeting tyrosinekinase inhibitor vandetanib, inhibiting VEGFR2, EGFR, and RET (rearranged during transfection), was tested in a randomized, double-blind, Phase II trial in combination with fulvestrant in postmenopausal patients with bone-predominant, HR-positive metastatic BC, with no improvement in bone-turnover markers or PFS or CB rates. ${ }^{119}$ The efficacy of the multitargeting tyrosine-kinase inhibitor dovitinib, inhibiting the fibroblast growth factor receptors (FGFRs) 1-3, VEGFR1-3, and other tyrosine-kinase receptors in combination with fulvestrant was assessed in a randomized, double-blind, Phase II study in postmenopausal patients with HR-positive, HER2-negative ABC that had progressed during or after prior endocrine therapy. ${ }^{120}$ Patients were stratified by FGF pathway-amplification status (amplification of FGFR1, 2 , and/or 3 versus no amplification), with subset analyses conducted according to a Bayesian design. The study was closed in advance after recruitment of 31 patients with FGFpathway amplification and 66 without, due to low frequency of FGF pathway-amplified cases. In the full population, the PFS hazard ratio of 0.68 (95\% CI 0.41-1.14) favoring dovitinib did not meet the criteria for superiority, and the same held true in the FGF pathway-unamplified subgroup (PFS hazard ratio 0.69$)$. On the contrary, the PFS hazard ratio of 0.64 (95\% CI 0.22-1.86) favoring dovitinib in the FGF pathway-amplified subgroup met the efficacy criteria. Dovitinib thus had promising activity in the FGF pathway-amplified subgroup, although the small sample precludes definitive conclusions, and efficacy in the FGF pathway-unamplified subgroup cannot be excluded.

\section{Combination with other agents}

In a Phase II randomized trial, bortezomib added to fulvestrant led to marginal improvement in PFS over fulvestrant alone. ${ }^{121}$ Preclinical studies have shown synergism among fulvestrant and several chemotherapeutic agents, ${ }^{122,123}$ and a single-arm Phase II trial of fulvestrant plus metronomic capecitabine reported a median PFS of 15 months. ${ }^{124}$

\section{Safety and tolerability}

Fulvestrant is well tolerated. The CONFIRM study ${ }^{65}$ reported the following grade 1-4 AEs with fulvestrant HD: gastrointestinal $20.2 \%$, joint disorders $18.8 \%$, injection-site reactions $13.6 \%$, hot flashes $8.3 \%$, urinary tract infection $2.2 \%$, 
ischemic cardiovascular disorders $1.4 \%$, thromboembolic events $0.8 \%$, vaginitis $0.8 \%$, osteoporosis $0.3 \%$, and weight gain $0.3 \%$. Grade $\geq 3$ AEs were gastrointestinal disturbances $2.2 \%$, joint disorders $2.2 \%$, thromboembolic events $0.6 \%$, injection-site reactions $0.3 \%$, and urinary tract infection $0.3 \%$. Serious AEs (SAEs) occurred in $9.7 \%$ of patients, but only $2.2 \%$ were causally related to the study treatment, and grade 5 SAEs occurred in $1.4 \%$ of patients. ${ }^{66}$ Comparing fulvestrant with anastrozole, data from the FALCON study showed a similar rate of SAEs (13\%). Grade $\geq 3$ AEs were reported in $22 \%$ of patients receiving fulvestrant and $18 \%$ of those receiving anastrozole, and grade $5 \mathrm{AEs}$ were $3 \%$ in both arms and not deemed causally related to treatment. The rate of arthralgia/back pain was $26 \%$ with fulvestrant and $18 \%$ with anastrozole. ${ }^{72}$ Other AEs were fatigue, hypertension, headache, insomnia, transaminitis, cough, anemia, dyspnea, and peripheral edema.

\section{Patient-focused perspectives, such as QoL, patient satisfaction/ acceptability, adherence, and uptake}

The good tolerability and efficacy of fulvestrant lead to maintained QoL. In the FALCON trial, health-related QoL, measured by the Trial Outcome Index (TOI) and the Functional Assessment of Cancer Therapy for Breast Cancer (FACT-B) total score, showed similar improvements in approximately a third of patients in the fulvestrant and anastrozole arms, and the time to deterioration did not differ significantly between arms. ${ }^{125}$ Similarly, no significant differences were found between fulvestrant and exemestane in terms of QoL in the EFECT trial. ${ }^{51}$ On the other hand, in PALOMA-3, adding palbociclib to fulvestrant significantly delayed the deterioration of global QoL and pain. ${ }^{110}$ In the CONFIRM trial, no differences were found in TOI scores between the two fulvestrant dosages. ${ }^{65}$ Treatment compliance with fulvestrant may be supported by its monthly IM administration, often provided at outpatient clinics, although patient preference for IM compared with oral administration has not been assessed and could change from patient to patient and over time.

\section{Conclusion}

Fulvestrant, the first SERD approved for clinical use in HRpositive $A B C$, is the single most active endocrine agent in untreated postmenopausal patients in the first-line metastatic setting, and is particularly suitable for combination therapy, due to the lack of significant drug interactions. It has more recently been approved for treatment in combination with the CDK4/6 inhibitors palbociclib (plus a GnRH agonist in premenopause) or abemaciclib (for the moment only in the US) in women with HR-positive, HER2-negative ABC who have received prior endocrine therapy.

Fulvestrant is now indicated as one of the first lines of endocrine therapy for ABC by all major guidelines, although the preferred sequence of endocrine agents in the metastatic setting has not been defined and may vary from patient to patient. Among the available drugs, those more commonly considered for first-line therapy in postmenopause are fulvestrant alone, AIs alone, and AIs plus CDK4/6 inhibitors. While CDK4/6 inhibitors have shown benefit, when added to an AI, in all subgroups, the real need for a combination treatment in all patients at the frontline is questioned, and the choice should consider disease-related (eg, disease-free interval, biological features, number and site of metastases), patient-related (performance status, age, comorbidity, patient preferences, compliance), and treatment-related (toxicity, suitability, acceptability) aspects. For postmenopausal patients relapsing during or shortly after ( $\leq 12$ months) adjuvant AI therapy, fulvestrant plus palbociclib is a logical choice. For those with de novo ABC and those not pretreated with an AI or relapsing $>1$ year from the end of adjuvant $\mathrm{AI}$, frontline treatment could be an AI plus CDK4/6 inhibitor, or also fulvestrant alone or even an $\mathrm{AI}$ alone in selected cases. As fulvestrant has been studied mainly in postmenopausal patients, its use in premenopause requires the association with a $\mathrm{GnRH}$ analog and regulatory aspects may vary in different countries. Further roles for fulvestrant are anticipated in combination with other targeted therapies like inhibitors of the PI3K-Akt-mTOR pathway. Meanwhile, new oral SERDs are being developed and will likely be licensed in the next few years.

\section{Disclosure}

AR has acted in an advisory role for Pfizer Pharmaceutical and received travel and accommodation expenses and speaker honoraria from Roche and Novartis. The other authors report no conflicts of interest in this work.

\section{References}

1. International Agency for Research on Cancer [webpage on the Internet]. Cancer Today; 2016. Available from: http://gco.iarc.fr/today. Accessed December 12, 2017.

2. Cancer Genome Atlas Network. Comprehensive molecular portraits of human breast tumours. Nature. 2012;490(7418):61-70.

3. Perou CM, Sørlie T, Eisen MB, et al. Molecular portraits of human breast tumours. Nature. 2000;406(6797):747-752.

4. Sorlie T, Tibshirani R, Parker J, et al. Repeated observation of breast tumor subtypes in independent gene expression data sets. Proc Natl Acad Sci U S A. 2003;100(14):8418-8423. 
5. Brenton JD, Carey LA, Ahmed AA, Caldas C. Molecular classification and molecular forecasting of breast cancer: ready for clinical application? J Clin Oncol. 2005;23(29):7350-7360.

6. Ades F, Zardavas D, Bozovic-Spasojevic I, et al. Luminal B breast cancer: molecular characterization, clinical management, and future perspectives. J Clin Oncol. 2014;32(25):2794-2803.

7. Goldhirsch A, Winer EP, Coates AS, et al. Personalizing the treatment of women with early breast cancer: highlights of the St Gallen International Expert Consensus on the Primary Therapy of Early Breast Cancer 2013. Ann Oncol. 2013;24(9):2206-2223.

8. Cardoso F, Costa A, Senkus E, et al. 3rd ESO-ESMO International Consensus Guidelines for Advanced Breast Cancer (ABC 3). Ann Oncol. 2017;28(1):16-33.

9. Musgrove EA, Sutherland RL. Biological determinants of endocrine resistance in breast cancer. Nat Rev Cancer. 2009;9(9):631-643.

10. Miller TW, Rexer BN, Garrett JT, Arteaga CL. Mutations in the phosphatidylinositol 3-kinase pathway: role in tumor progression and therapeutic implications in breast cancer. Breast Cancer Res. 2011; 13(6):224.

11. Frogne T, Jepsen JS, Larsen SS, Fog CK, Brockdorff BL, Lykkesfeldt AE. Antiestrogen-resistant human breast cancer cells require activated protein kinase B/Akt for growth. Endocr Relat Cancer. 2005;12(3):599-614.

12. Yamnik RL, Holz MK. mTOR/S6K1 and MAPK/RSK signaling pathways coordinately regulate estrogen receptor $\alpha$ serine 167 phosphorylation. FEBS Lett. 2010;584(1):124-128.

13. Hui R, Finney GL, Carroll JS, Lee CS, Musgrove EA, Sutherland RL. Constitutive overexpression of cyclin D1 but not cyclin E confers acute resistance to antiestrogens in T-47D breast cancer cells. Cancer Res. 2002;62(23):6916-6923.

14. Alves CL, Elias D, Lyng M, et al. High CDK6 protects cells from fulvestrant-mediated apoptosis and is a predictor of resistance to fulvestrant in estrogen receptor-positive metastatic breast cancer. Clin Cancer Res. 2016;22(22):5514-5526.

15. Thangavel C, Dean JL, Ertel A, et al. Therapeutically activating RB: reestablishing cell cycle control in endocrine therapy-resistant breast cancer. Endocr Relat Cancer. 2011;18(3):333-345.

16. Jeselsohn R, Buchwalter G, de Angelis C, Brown M, Schiff R. ESR1 mutations: a mechanism for acquired endocrine resistance in breast cancer. Nat Rev Clin Oncol. 2015;12(10):573-583.

17. Wakeling AE, Dukes M, Bowler J. A potent specific pure antiestrogen with clinical potential. Cancer Res. 1991;51(15):3867-3873.

18. Osborne CK, Schiff R. Estrogen-receptor biology: continuing progress and therapeutic implications. J Clin Oncol. 2005;23(8):1616-1622.

19. Jordan VC, O'Malley BW. Selective estrogen-receptor modulators and antihormonal resistance in breast cancer. J Clin Oncol. 2007;25(36):5815-5824.

20. Osborne CK, Wakeling A, Nicholson RI. Fulvestrant: an oestrogen receptor antagonist with a novel mechanism of action. Br J Cancer. 2004;90 Suppl 1:S2-S6.

21. Kumar V, Green S, Stack G, Berry M, Jin JR, Chambon P. Functional domains of the human estrogen receptor. Cell. 1987;51(6):941-951.

22. Kato S, Endoh H, Masuhiro Y, et al. Activation of the estrogen receptor through phosphorylation by mitogen-activated protein kinase. Science. 1995;270(5241):1491-1494.

23. Fawell SE, White R, Hoare S, Sydenham M, Page M, Parker MG. Inhibition of estrogen receptor-DNA binding by the "pure" antiestrogen ICI 164,384 appears to be mediated by impaired receptor dimerization. Proc Natl Acad Sci U S A. 1990;87(17):6883-6887.

24. Dauvois S, White R, Parker MG. The antiestrogen ICI 182780 disrupts estrogen receptor nucleocytoplasmic shuttling.JCell Sci.1993;106(Pt4): 1377-1388.

25. Wakeling AE. Use of pure antioestrogens to elucidate the mode of action of oestrogens. Biochem Pharmacol. 1995;49(11):1545-1549.

26. Morales L, Neven P, Timmerman D, et al. Prospective assessment of the endometrium in postmenopausal breast cancer patients treated with fulvestrant. Breast Cancer Res Treat. 2009;117(1):77-81.
27. Peekhaus NT, Chang T, Hayes EC, et al. Distinct effects of the antiestrogen Faslodex on the stability of estrogen receptors- $\alpha$ and $-\beta$ in the breast cancer cell line MCF-7. J Mol Endocrinol. 2004;32(3):987-995.

28. Mishra AK, Abrahamsson A, Dabrosin C. Fulvestrant inhibits growth of triple negative breast cancer and synergizes with tamoxifen in $\mathrm{ER} \alpha$ positive breast cancer by up-regulation of ER $\beta$. Oncotarget. 2016;7(35):56876-56888.

29. McClelland RA, Gee JM, Francis AB, et al. Short-term effects of pure anti-oestrogen ICI 182780 treatment on oestrogen receptor, epidermal growth factor receptor and transforming growth factoralpha protein expression in human breast cancer. Eur J Cancer. 1996;32A(3):413-416.

30. Inoue A, Yoshida N, Omoto Y, et al. Development of cDNA microarray for expression profiling of estrogen-responsive genes. J Mol Endocrinol. 2002;29(2):175-192.

31. dos Santos EG, Dieudonne MN, Pecquery R, le Moal V, Giudicelli Y, Lacasa D. Rapid nongenomic E2 effects on p42/p44 MAPK, activator protein-1, and cAMP response element binding protein in rat white adipocytes. Endocrinology. 2002;143(3):930-940.

32. Hu XF, Veroni M, de Luise M, et al. Circumvention of tamoxifen resistance by the pure anti-estrogen ICI 182,780. Int J Cancer. 1993;55(5):873-876.

33. Lykkesfeldt AE, Madsen MW, Briand P. Altered expression of estrogenregulated genes in a tamoxifen-resistant and ICI 164,384 and ICI 182,780 sensitive human breast cancer cell line, MCF-7/TAMR-1. Cancer Res. 1994;54(6):1587-1595.

34. de Cupis A, Noonan D, Pirani P, Ferrera A, Clerico L, Favoni RE. Comparison between novel steroid-like and conventional nonsteroidal antioestrogens in inhibiting oestradiol- and IGF-I-induced proliferation of human breast cancer-derived cells. Br J Pharmacol. 1995;116(5):2391-2400.

35. Lykkesfeldt AE, Larsen SS, Briand P. Human breast cancer cell lines resistant to pure anti-estrogens are sensitive to tamoxifen treatment. Int J Cancer. 1995;61(4):529-534.

36. Osborne CK, Coronado-Heinsohn EB, Hilsenbeck SG, et al. Comparison of the effects of a pure steroidal antiestrogen with those of tamoxifen in a model of human breast cancer. $J$ Natl Cancer Inst. 1995;87(10):746-750.

37. Dowsett M, Nicholson RI, Pietras RJ. Biological characteristics of the pure antiestrogen fulvestrant: overcoming endocrine resistance. Breast Cancer Res Treat. 2005;93 Suppl 1:S11-S18.

38. DeFriend DJ, Howell A, Nicholson RI, et al. Investigation of a new pure antiestrogen (ICI 182780) in women with primary breast cancer. Cancer Res. 1994;54(2):408-414.

39. Robertson JF, Nicholson RI, Bundred NJ, et al. Comparison of the shortterm biological effects of 7 $\alpha$-[9-(4,4,5,5,5-pentafluoropentylsulfinyl)nonyl] estra-1,3,5, (10)-triene-3,17 $\beta$-diol (Faslodex) versus tamoxifen in postmenopausal women with primary breast cancer. Cancer Res. 2001;61(18):6739-6746.

40. Agrawal A, Robertson JF, Cheung KL, et al. Biological effects of fulvestrant on estrogen receptor positive human breast cancer: short, medium and long-term effects based on sequential biopsies. Int $J$ Cancer. 2016;138(1):146-159.

41. Kuter I, Gee JM, Hegg R, et al. Dose-dependent change in biomarkers during neoadjuvant endocrine therapy with fulvestrant: results from NEWEST, a randomized phase II study. Breast Cancer Res Treat. 2012;133(1):237-246.

42. Deeks ED. Fulvestrant: a review in advanced breast cancer not previously treated with endocrine therapy. Drugs. 2018;78(1): 131-137.

43. Howell A, DeFriend D, Robertson J, Blamey R, Walton P. Response to a specific antioestrogen (ICI 182780) in tamoxifen-resistant breast cancer. Lancet. 1995;345(8941):29-30.

44. Howell A, DeFriend DJ, Robertson JF, et al. Pharmacokinetics, pharmacological and anti-tumour effects of the specific anti-oestrogen ICI 182780 in women with advanced breast cancer. Br J Cancer. 1996;74(2):300-308. 
45. Robertson JF, Erikstein B, Osborne KC, et al. Pharmacokinetic profile of intramuscular fulvestrant in advanced breast cancer. Clin Pharmacokinet. 2004;43(8):529-538

46. Robertson JF, Odling-Smee W, Holcombe C, Kohlhardt SR, Harrison MP. Pharmacokinetics of a single dose of fulvestrant prolonged-release intramuscular injection in postmenopausal women awaiting surgery for primary breast cancer. Clin Ther. 2003;25(5):1440-1452.

47. Robertson JF, Harrison MP. Equivalent single-dose pharmacokinetics of two different dosing methods of prolonged-release fulvestrant ('Faslodex') in postmenopausal women with advanced breast cancer. Cancer Chemother Pharmacol. 2003;52(4):346-348.

48. Robertson JF. Fulvestrant (Faslodex): how to make a good drug better. Oncologist. 2007;12(7):774-784.

49. Ohno S, Rai Y, Iwata H, et al. Three dose regimens of fulvestrant in postmenopausal Japanese women with advanced breast cancer: results from a double-blind, phase II comparative study (FINDER1). Ann Oncol. 2010;21(12):2342-2347.

50. Pritchard KI, Rolski J, Papai Z, et al. Results of a phase II study comparing three dosing regimens of fulvestrant in postmenopausal women with advanced breast cancer (FINDER2). Breast Cancer Res Treat. 2010;123(2):453-461.

51. Chia S, Gradishar W, Mauriac L, et al. Double-blind, randomized placebo controlled trial of fulvestrant compared with exemestane after prior nonsteroidal aromatase inhibitor therapy in postmenopausal women with hormone receptor-positive, advanced breast cancer: results from EFECT. J Clin Oncol. 2008;26(10):1664-1670.

52. McCormack P, Sapunar F. Pharmacokinetic profile of the fulvestrant loading dose regimen in postmenopausal women with hormone receptor-positive advanced breast cancer. Clin Breast Cancer. 2008;8(4):347-351.

53. Oakman C, Moretti E, Santarpia L, Di Leo A. Fulvestrant in the management of postmenopausal women with advanced, endocrineresponsive breast cancer. Future Oncol. 2011;7(2):173-186.

54. Lee CI, Goodwin A, Wilcken N. Fulvestrant for hormone-sensitive metastatic breast cancer. Cochrane Database Syst Rev. 2017;1:CD011093.

55. Ingle JN, Suman VJ, Rowland KM, et al. Fulvestrant in women with advanced breast cancer after progression on prior aromatase inhibitor therapy: North Central Cancer Treatment Group Trial N0032. J Clin Oncol. 2006;24(7):1052-1056.

56. Perey L, Paridaens R, Hawle H, et al. Clinical benefit of fulvestrant in postmenopausal women with advanced breast cancer and primary or acquired resistance to aromatase inhibitors: final results of phase II Swiss Group for Clinical Cancer Research Trial (SAKK 21/00). Ann Oncol. 2007;18(1):64-69.

57. Franco S, Perez A, Tan-Chiu E, Frankel C, Vogel CL. Response to fulvestrant in heavily pretreated postmenopausal women: a singlecenter experience. Breast Cancer Res Treat. 2004;88(2):103-108.

58. Steger GG, Bartsch R, Wenzel C, et al. Fulvestrant ('Faslodex') in pre-treated patients with advanced breast cancer: a single-centre experience. Eur J Cancer. 2005;41(17):2655-2661.

59. Howell A, Robertson JF, Albano JQ, et al. Fulvestrant, formerly ICI 182,780 , is as effective as anastrozole in postmenopausal women with advanced breast cancer progressing after prior endocrine treatment. $J$ Clin Oncol. 2002;20(16):3396-3403.

60. Osborne CK, Pippen J, Jones SE, et al. Double-blind, randomized trial comparing the efficacy and tolerability of fulvestrant versus anastrozole in postmenopausal women with advanced breast cancer progressing on prior endocrine therapy: results of a North American trial. J Clin Oncol. 2002;20(16):3386-3395.

61. Robertson JF, Osborne CK, Howell A, et al. Fulvestrant versus anastrozole for the treatment of advanced breast carcinoma in postmenopausal women: a prospective combined analysis of two multicenter trials. Cancer. 2003;98(2):229-238.

62. Mauriac L, Pippen JE, Albano JQ, Gertler SZ, Osborne CK. Fulvestrant (Faslodex) versus anastrozole for the second-line treatment of advanced breast cancer in subgroups of postmenopausal women with visceral and non-visceral metastases: combined results from two multicentre trials. Eur J Cancer. 2003;39(9):1228-1233.
63. Howell A, Pippen J, Elledge RM, et al. Fulvestrant versus anastrozole for the treatment of advanced breast carcinoma: a prospectively planned combined survival analysis of two multicenter trials. Cancer. 2005;104(2):236-239.

64. Howell A, Robertson JF, Abram P, et al. Comparison of fulvestrant versus tamoxifen for the treatment of advanced breast cancer in postmenopausal women previously untreated with endocrine therapy: a multinational, double-blind, randomized trial. J Clin Oncol. 2004;22(9):1605-1613.

65. Di Leo A, Jerusalem G, Petruzelka L, et al. Results of the CONFIRM phase III trial comparing fulvestrant $250 \mathrm{mg}$ with fulvestrant $500 \mathrm{mg}$ in postmenopausal women with estrogen receptor-positive advanced breast cancer. J Clin Oncol. 2010;28(30):4594-4600.

66. Di Leo A, Jerusalem G, Petruzelka L, et al. Final overall survival: fulvestrant $500 \mathrm{mg}$ vs $250 \mathrm{mg}$ in the randomized CONFIRM trial. $J$ Natl Cancer Inst. 2014;106(1):djt337.

67. Di Leo A, Jerusalem G, Torres R, et al. First-line vs second-line fulvestrant for hormone receptor-positive advanced breast cancer: a post-hoc analysis of the CONFIRM study. Breast. 2018;38:144-149.

68. Jeselsohn R, Barry WT, Migliaccio I, et al. TransCONFIRM: identification of a genetic signature of response to fulvestrant in advanced hormone receptor-positive breast cancer. Clin Cancer Res. 2016;22(23):5755-5764.

69. Robertson JF, Llombart-Cussac A, Rolski J, et al. Activity of fulvestrant $500 \mathrm{mg}$ versus anastrozole $1 \mathrm{mg}$ as first-line treatment for advanced breast cancer: results from the FIRST study. J Clin Oncol. 2009;27(27):4530-4535.

70. Robertson JF, Lindemann JP, Llombart-Cussac A, et al. Fulvestrant $500 \mathrm{mg}$ versus anastrozole $1 \mathrm{mg}$ for the first-line treatment of advanced breast cancer: follow-up analysis from the randomized 'FIRST' study. Breast Cancer Res Treat. 2012;136(2):503-511.

71. Ellis MJ, Llombart-Cussac A, Feltl D, et al. Fulvestrant $500 \mathrm{mg}$ versus anastrozole $1 \mathrm{mg}$ for the first-line treatment of advanced breast cancer: overall survival analysis from the phase II FIRST study. J Clin Oncol. 2015;33(32):3781-3787.

72. Robertson JF, Bondarenko IM, Trishkina E, et al. Fulvestrant $500 \mathrm{mg}$ versus anastrozole $1 \mathrm{mg}$ for hormone receptor-positive advanced breast cancer (FALCON): an international, randomised, double-blind, phase 3 trial. Lancet. 2016;388(10063):2997-3005.

73. Young OE, Renshaw L, Macaskill EJ, et al. Effects of fulvestrant $750 \mathrm{mg}$ in premenopausal women with oestrogen-receptor-positive primary breast cancer. Eur J Cancer. 2008;44(3):391-399.

74. Masci G, Gandini C, Zuradelli M, et al. Fulvestrant for advanced male breast cancer patients: a case series. Ann Oncol. 2011;22(4):985.

75. Zagouri F, Sergentanis TN, Chrysikos D, Dimopoulos MA, Psaltopoulou T. Fulvestrant and male breast cancer: a pooled analysis. Breast Cancer Res Treat. 2015;149(1):269-275.

76. Jelovac D, Macedo L, Goloubeva OG, Handratta V, Brodie AM. Additive antitumor effect of aromatase inhibitor letrozole and antiestrogen fulvestrant in a postmenopausal breast cancer model. Cancer Res. 2005;65(12):5439-5444.

77. Robertson JF, Dixon JM, Sibbering DM, et al. A randomized trial to assess the biological activity of short-term (pre-surgical) fulvestrant $500 \mathrm{mg}$ plus anastrozole versus fulvestrant $500 \mathrm{mg}$ alone or anastrozole alone on primary breast cancer. Breast Cancer Res. 2013;15(2):R18.

78. Bergh J, Jönsson PE, Lidbrink EK, et al. FACT: an open-label randomized phase III study of fulvestrant and anastrozole in combination compared with anastrozole alone as first-line therapy for patients with receptor-positive postmenopausal breast cancer. J Clin Oncol. 2012;30(16):1919-1925.

79. Mehta RS, Barlow WE, Albain KS, et al. Combination anastrozole and fulvestrant in metastatic breast cancer. $N$ Engl J Med. 2012;367(5):435-444.

80. Johnston SR, Kilburn LS, Ellis P, et al. Fulvestrant plus anastrozole or placebo versus exemestane alone after progression on non-steroidal aromatase inhibitors in postmenopausal patients with hormone-receptor-positive locally advanced or metastatic breast cancer (SoFEA): a composite, multicentre, phase 3 randomised trial. Lancet Oncol. 2013;14(10):989-998. 
81. Fribbens C, O'Leary B, Kilburn L, et al. Plasma ESR1 mutations and the treatment of estrogen receptor-positive advanced breast cancer. J Clin Oncol. 2016;34(25):2961-2968.

82. Robertson JF, Steger GG, Neven P, et al. Activity of fulvestrant in HER2-overexpressing advanced breast cancer. Ann Oncol. 2010;21(6):1246-1253.

83. Sonne-Hansen K, Norrie IC, Emdal KB, et al. Breast cancer cells can switch between estrogen receptor alpha and ErbB signaling and combined treatment against both signaling pathways postpones development of resistance. Breast Cancer Res Treat. 2010;121(3): 601-613.

84. Chen Q, Weng Z, LuY, et al. An experimental analysis of the molecular effects of trastuzumab (Herceptin) and fulvestrant (Falsodex), as single agents or in combination, on human HR+/HER2+ breast cancer cell lines and mouse tumor xenografts. PLoS One. 2017;12(1):e0168960.

85. Massarweh S, Tham YL, Huang J, et al. A phase II neoadjuvant trial of anastrozole, fulvestrant, and gefitinib in patients with newly diagnosed estrogen receptor positive breast cancer. Breast Cancer Res Treat. 2011;129(3):819-827.

86. Carlson RW, O’Neill A, Vidaurre T, Gomez HL, Badve SS, Sledge GW. A randomized trial of combination anastrozole plus gefitinib and of combination fulvestrant plus gefitinib in the treatment of postmenopausal women with hormone receptor positive metastatic breast cancer. Breast Cancer Res Treat. 2012;133(3):1049-1056.

87. Burstein HJ, Cirrincione CT, Barry WT, et al. Endocrine therapy with or without inhibition of epidermal growth factor receptor and human epidermal growth factor receptor 2: a randomized, doubleblind, placebo-controlled phase III trial of fulvestrant with or without lapatinib for postmenopausal women with hormone receptor-positive advanced breast cancer-CALGB 40302 (Alliance). J Clin Oncol. 2014;32(35):3959-3966.

88. Robertson JF, Ferrero JM, Bourgeois H, et al. Ganitumab with either exemestane or fulvestrant for postmenopausal women with advanced, hormone-receptor-positive breast cancer: a randomised, controlled, double-blind, phase 2 trial. Lancet Oncol. 2013;14(3):228-235.

89. Frogne T, Benjaminsen RV, Sonne-Hansen K, et al. Activation of ErbB3, EGFR and Erk is essential for growth of human breast cancer cell lines with acquired resistance to fulvestrant. Breast Cancer Res Treat. 2009;114(2):263-75.

90. Zaman K, Winterhalder R, Mamot C, et al. Fulvestrant with or without selumetinib, a MEK 1/2 inhibitor, in breast cancer progressing after aromatase inhibitor therapy: a multicentre randomized placebocontrolled double-blind phase II trial, SAKK 21/08. Eur J Cancer. 2015;51(10):1212-1220.

91. Zmajkovicova K, Jesenberger V, Catalanotti F, Baumgartner C, Reyes $\mathrm{G}$, Baccarini M. MEK1 is required for PTEN membrane recruitment, Akt regulation, and the maintenance of peripheral tolerance. $\mathrm{Mol} \mathrm{Cell}$. 2013;50(1):43-55.

92. Bosch A, Li Z, Bergamaschi A, et al. PI3K inhibition results in enhanced estrogen receptor function and dependence in hormone receptor-positive breast cancer. Sci Transl Med. 2015;7(283):283ra51.

93. Miller TW, Balko JM, Fox EM, et al. ER $\alpha$-dependent E2F transcription can mediate resistance to estrogen deprivation in human breast cancer. Cancer Discov. 2011;1(4):338-351.

94. Ma CX, Luo J, Naughton M, et al. A phase I trial of BKM120 (buparlisib) in combination with fulvestrant in postmenopausal women with estrogen receptor-positive metastatic breast cancer. Clin Cancer Res. 2016;22(7):1583-1591.

95. Baselga J, Im SA, Iwata $H$, et al. Buparlisib plus fulvestrant versus placebo plus fulvestrant in postmenopausal, hormone receptorpositive, HER2-negative, advanced breast cancer (BELLE-2): a randomised, double-blind, placebo-controlled, phase 3 trial. Lancet Oncol. 2017;18(7):904-916.

96. Di Leo A, Johnston S, Lee KS, et al. Buparlisib plus fulvestrant in postmenopausal women with hormone-receptor-positive, HER2-negative, advanced breast cancer progressing on or after mTOR inhibition (BELLE-3): a randomised, double-blind, placebo-controlled, phase 3 trial. Lancet Oncol. 2018;19(1):87-100.
97. Sun SY, Rosenberg LM, Wang X, et al. Activation of Akt and eIF4E survival pathways by rapamycin-mediated mammalian target of rapamycin inhibition. Cancer Res. 2005;65(16):7052-7058.

98. Krop IE, Mayer IA, Ganju V, et al. Pictilisib for oestrogen receptorpositive, aromatase inhibitor-resistant, advanced or metastatic breast cancer (FERGI): a randomised, double-blind, placebo-controlled, phase 2 trial. Lancet Oncol. 2016;17(6):811-821.

99. Juric D, Rodon J, Tabernero J, et al. Phosphatidylinositol 3-kinase $\alpha$-selective inhibition with alpelisib (BYL719) in PIK3CA-altered solid tumors: results from the first-in-human study. J Clin Oncol. 2018;36(13):1291-1299.

100. Juric D, Krop I, Ramanathan RK, et al. Phase I dose-escalation study of taselisib, an oral PI3K Inhibitor, in patients with advanced solid tumors. Cancer Discov. 2017;7(7):704-715.

101. Baselga J, Dent SF, Cortés J, et al. Phase III study of taselisib (GDC0032) + fulvestrant (FULV) v FULV in patients (pts) with estrogen receptor (ER)-positive, PIK3CA-mutant (MUT), locally advanced or metastatic breast cancer (MBC): Primary analysis from SANDPIPER. J Clin Oncol. 2018;36.

102. Ma CX, Sanchez C, Gao F, et al. A phase I study of the Akt inhibitor MK-2206 in combination with hormonal therapy in postmenopausal women with estrogen receptor-positive metastatic breast cancer. Clin Cancer Res. 2016;22(11):2650-2658.

103. Kornblum N, Zhao F, Manola J, et al. Randomized Phase II Trial of Fulvestrant Plus Everolimus or Placebo in Postmenopausal Women With Hormone Receptor-Positive, Human Epidermal Growth Factor Receptor 2-Negative Metastatic Breast Cancer Resistant to Aromatase Inhibitor Therapy: Results of PrE0102. J Clin Oncol. 2018;36(16):1556-1563.

104. Finn RS, Dering J, Conklin D, et al. PD 0332991, a selective cyclin D kinase 4/6 inhibitor, preferentially inhibits proliferation of luminal estrogen receptor-positive human breast cancer cell lines in vitro. Breast Cancer Res. 2009;11(5):R77.

105. Turner NC, Ro J, André F, et al. Palbociclib in hormone-receptorpositive advanced breast cancer. NEngl JMed. 2015;373(3):209-219.

106. Cristofanilli M, Turner NC, Bondarenko I, et al. Fulvestrant plus palbociclib versus fulvestrant plus placebo for treatment of hormonereceptor-positive, HER2-negative metastatic breast cancer that progressed on previous endocrine therapy (PALOMA-3): final analysis of the multicentre, double-blind, phase 3 randomised controlled trial. Lancet Oncol. 2016;17(4):425-439.

107. Loibl S, Turner NC, Ro J, et al. Palbociclib combined with fulvestrant in premenopausal women with advanced breast cancer and prior progression on endocrine therapy: PALOMA-3 results. Oncologist. 2017;22(9):1028-1038.

108. Turner NC, Finn RS, Martin M, et al. Clinical considerations of the role of palbociclib in the management of advanced breast cancer patients with and without visceral metastases. Ann Oncol. 2018;29(3):669-680.

109. Verma S, Bartlett $\mathrm{CH}$, Schnell $\mathrm{P}$, et al. Palbociclib in combination with fulvestrant in women with hormone receptor-positive/HER2negative advanced metastatic breast cancer: detailed safety analysis from a multicenter, randomized, placebo-controlled, phase III study (PALOMA-3). Oncologist. 2016;21(10):1165-1175.

110. Harbeck N, Iyer S, Turner N, et al. Quality of life with palbociclib plus fulvestrant in previously treated hormone receptor-positive, HER2negative metastatic breast cancer: patient-reported outcomes from the PALOMA-3 trial. Ann Oncol. 2016;27(6):1047-1054.

111. Gianni L, Bisagni G, Colleoni M, et al. Neoadjuvant treatment with trastuzumab and pertuzumab plus palbociclib and fulvestrant in HER2-positive, ER-positive breast cancer (NA-PHER2): an exploratory, open-label, phase 2 study. Lancet Oncol. 2018;19(2):249-256.

112. Sledge GW Jr, Toi M, Neven P, et al. MONARCH 2: abemaciclib in combination with fulvestrant in women with HR+/HER2- advanced breast cancer who had progressed while receiving endocrine therapy. J Clin Oncol. 2017;35(25):2875-2884.

113. Slamon DJ, Neven P, Chia S, et al. Phase III Randomized Study of Ribociclib and Fulvestrant in Hormone Receptor-Positive, Human Epidermal Growth Factor Receptor 2-Negative Advanced Breast Cancer: MONALEESA-3. J Clin Oncol. Epub 2018 Jun 3. 
114. Herrera-Abreu MT, Palafox M, Asghar U, et al. Early adaptation and acquired resistance to CDK4/6 inhibition in estrogen receptor-positive breast cancer. Cancer Res. 2016;76(8):2301-2313.

115. O'Brien NA, Di Tomaso E, Ayala R, et al. In vivo efficacy of combined targeting of CDK4/6, ER and PI3K signaling in ER+ breast cancer. Cancer Res. 2014;74(19 Suppl):4756.

116. Tolaney SM, Forero-Torres A, Boni V, et al. Ribociclib + fulvestrant in postmenopausal women with HR+, HER2-advanced breast cancer (ABC). Cancer Res. 2017;77(4 Suppl):P4-22-12.

117. Forero A, Han HS, Dees EC, et al. Phase IB study to assess the safety, tolerability, and clinical activity of gedatolisib in combination with palbociclib and either letrozole or fulvestrant in women with metastatic or locally advanced/recurrent breast cancer (B2151009). Poster presented at: 2017 San Antonio Breast Cancer Symposium; December 6-10, 2017; San Antonio, TX.

118. Martín M, Loibl S, von Minckwitz G, et al. Phase III trial evaluating the addition of bevacizumab to endocrine therapy as first-line treatment for advanced breast cancer: the letrozole/fulvestrant and avastin (LEA) study. J Clin Oncol. 2015;33(9):1045-1052.

119. Clemons MJ, Cochrane B, Pond GR, et al. Randomised, phase II, placebo-controlled, trial of fulvestrant plus vandetanib in postmenopausal women with bone only or bone predominant, hormone-receptorpositive metastatic breast cancer (MBC): the OCOG ZAMBONEY study. Breast Cancer Res Treat. 2014;146(1):153-162.
120. Musolino A, Campone M, Neven P, et al. Phase II, randomized, placebocontrolled study of dovitinib in combination with fulvestrant in postmenopausal patients with $\mathrm{HR}^{+}, \mathrm{HER}^{-}$breast cancer that had progressed during or after prior endocrine therapy. Breast Cancer Res. 2017;19(1):18.

121. Adelson K, Ramaswamy B, Sparano JA, et al. Randomized phase II trial of fulvestrant alone or in combination with bortezomib in hormone receptor-positive metastatic breast cancer resistant to aromatase inhibitors: a New York Cancer Consortium trial. NPJ Breast Cancer. 2016;2:16037.

122. Dolfi SC, Jäger AV, Medina DJ, Haffty BG, Yang JM, Hirshfield KM. Fulvestrant treatment alters MDM2 protein turnover and sensitivity of human breast carcinoma cells to chemotherapeutic drugs. Cancer Lett. 2014;350(1-2):52-60.

123. Jiang D, Huang Y, Han N, et al. Fulvestrant, a selective estrogen receptor down-regulator, sensitizes estrogen receptor negative breast tumors to chemotherapy. Cancer Lett. 2014;346(2):292-299.

124. Schwartzberg LS, Wang G, Somer BG, et al. Phase II trial of fulvestrant with metronomic capecitabine for postmenopausal women with hormone receptor-positive, HER2-negative metastatic breast cancer Clin Breast Cancer. 2014;14(1):13-19.

125. Robertson JF, Cheung KL, Noguchi S, et al. Health-related quality of life from the FALCON phase III randomised trial of fulvestrant 500 $\mathrm{mg}$ versus anastrozole for hormone receptor-positive advanced breast cancer. Eur J Cancer. 2018;94:206-215.
Cancer Management and Research

\section{Publish your work in this journal}

Cancer Management and Research is an international, peer-reviewed open access journal focusing on cancer research and the optimal use of preventative and integrated treatment interventions to achieve improved outcomes, enhanced survival and quality of life for the cancer patient. The manuscript management system is completely online and includes

\section{Dovepress}

a very quick and fair peer-review system, which is all easy to use. Visit http://www.dovepress.com/testimonials.php to read real quotes from published authors. 